Бомбицкий A.M.

\title{
ТЕОРИЯ АДМИНИСТРАТИВНОЙ ОТВЕТСТВЕННОСТИ И ЕЕ РЕАЛИЗАЦИЯ ЗА НАРУШЕНИЯ ЗАКОНОДАТЕЛЬСТВА О КОНТРАКТНОЙ СИСТЕМЕ В СФЕРЕ ЗАКУПОК ТОВАРОВ, РАБОТ, УСЛУГ ДЛЯ ОБЕСПЕЧЕНИЯ ГОСУДАРСТВЕННЫХ И МУНИЦИПАЛЬНЫХ НУЖД
}

\begin{abstract}
Аннотация: Предметом статьи являются проблемы правового и организационного характера, связанные с реализацией мер административной ответственности за нарушение законодательства о контрактной системе в сфрере закупок товаров, работ, услуг для обеспечения государственных и муниципальных нужд. Автором подробно проводится теоретико-правовой анализ концепций административной ответственности. Рассматриваются авторские позиции относительно понятия правового регулирования административной ответственности. Основное внимание в статье уделяется разработки методов и методологии административно-правового регулирования ответственности в административном праве. Рассматриваются авторские позиции Методологическую основу статьи составили современные достижения теории познания. В процессе исследования применялись общефилософрский, теоретический, общефрилософрские методы (диалектика, системный метод, анализ, синтез, аналогия, дедукция, наблюдение, моделирование), традиционно правовые методы (формально-логический), а также методы, используемые в конкретносоциологических исследованиях (статистические, экспертные оценки и др.). Основной вывод, который сделан по итогам исследования, состоит в том, что в настоящее время для обеспечения правопорядка в сфере закупок товаров, работ, услуг для обеспечения государственных и муниципальных нужд необходимо совершенствовать формы и методы административно-правового регулирования в соответствующей сорере. Основным вкладом, который сделан авторами в настоящей статье это необходимость развития административно-правового регулирования ответственности в сфрере государственных закупок. Новизна статьи заключается в разработке предложений по развитию форм и методов государственного регулирования административной ответственности, а также создание правовых и организационных гарантий законности в сорере госзакупок.
\end{abstract}

Ключевые слова: Контракт, услуга, закупка, ответственность, аукцион, система, работа, нужд, поставка, обеспечения.

Review: The subject of the research is the range of legal and organizational problems of administrative liability application in the cases of violation of legislation on the contract system in the sphere of state and municipal purchasing. The author carries 
out the theoretical and legal analysis of the concepts of administrative activity. The paper presents the author's positions on the concept of legal regulation of administrative activity. The main attention is paid to the development of methods and methodology of administrative-legal regulation of liability in administrative law. The methodology of the research comprises the recent achievements of epistemology. The author applies the general philosophical and theoretical methods (dialectics, the systems method, analysis, synthesis, analogy, deduction, observation, modeling), the traditional legal methods (formal-logical), and the methods of special sociological research (the statistical methods, expert assessments, etc.). The author concludes that recently in order to provide legality in the sphere of state and municipal purchasing, it is necessary to enhance the forms and methods of administrative-legal regulation of this sphere. The main contribution of the author is the conclusion about the necessity to develop administrative-legal regulation of liability in the sphere of state purchasing. The novelty of the research lies in the suggestions about the development of forms and methods of government regulation of administrative liability and the creation of legal and organizational guarantees of legality in the sphere of state purchasing.

Keywords: Work, system, auction, liability, purchasing, service, contract, needs, delivery, provision.

Г

оворя об административной ответственности, установленной за нарушение законодательства за нарушения законодательства о контрактной системе в сорере закупок товаров, работ, услуг для обеспечения государственных и муниципальных нужд, следует несколько слов сказать о содержании юридической ответственности. Обусловлено это тем, что административная ответственность является составной частью юридической ответственности. Можно провести логическую взаимосвязь между различными видами юридической ответственности, а также отметить, что между юридической ответственностью, административной ответственностью, а также административной ответственностью за нарушение законодательства о контрактной системе в сфере закупок товаров, работ, услуг для обеспечения государственных и муниципальных нужд существует диалектическая взаимосвязь общего, единичного и особенного.

Нужно отметить, что выявление характерных черт понятия «юридическая ответственность» затруднено тем, что содержание, которое вкладывается в это понятие, в юридической литературе понимается неоднозначно. Здесь наблюдается часто встречающаяся ситуация: когда один и тот же термин несет разную смысловую нагрузку в зависимости от ряда фракторов (контекста работы, особенностей авторского подхода к проблеме и т.д.). Вместе с тем в любой отрасли науки происходит по мере углубления и расширения знаний, уточнения понятий и определений пересмотр устоявшейся терминологии. Но в любом случае, как справедливо отметил С.С. Алексе- 
ев, «...нельзя забывать важнейших требований, предъявляемых к научной терминологии, - ее однозначности, строгой определенности, ясности, устойчивости, совместимости со всем комплексом употребляемых в науке терминов. Обогащение понятийного аппарата науки должно происходить не за счет утраты точности терминов, так как утрачивается определенность научных понятий»[1]. Как отмечает Л.С. Явич, что «...пока еще не удалось создать столь важную для правовой практики общую теорию юридической ответственности» [2].

Следует сказать, что в настоящее время в период формирования правового государства в Российской Федерации как никогда велика роль одного из основополагающих институтов права - юридической ответственности, которая является разновидностью ответственности. Вообще понятие «ответственность» производно от глагола «отвечать» (дать ответ, подать весть и т.д.) [3].

Следует отметить, что ответственность - сложное и многостороннее понятие, имеющее прежде всего философский характер. Единого понятия ответственности не существует. В философской науке делается акцент на долг лица перед другими лицами или обществом, в связи с чем с философской точки зрения юридическая ответственность как правовое явление представляет собой единство содержания и формы, то есть не только определенное состояние, изменяющее правовой статус правонарушителя, но и «особую процедуру ее возложения (применения), исполнения и осуществления» [4]. В общественных науках речь идет о социальной ответственности, содержание которой, помимо правосознания, формируют и другие сферы общественного сознания, ее основанием выступают не только общественно вредные, но и общественно нейтральные и общественно полезные поступки [5].

Социальная роль права предопределила, что под юридической ответственностью как разновидностью социальной ответственности одни авторы понимают обязанность отвечать (или дать отчет за свои противоправные действия) [6], другие - реализацию санкции правовой нормы [7], третьи - разновидность обязанности, которая носит ущербный, нежелательный характер для субъекта, на которого она возлагается [8]. Признаками юридической ответственности является то, что она опирается на государственное принуждение, связана с негативной государственно-правовой оценкой за совершенное деяние, с обязанностью правонарушителя претерпевать лишения, связанные с изменением его статуса [9]. Таким образом, в литературе широко исследуется негативный (ретроспективный) аспект юридической ответственности. В целом же юридическая ответственность рассматривается как разновидность социальной ответственности, как правовая категория, как правоотношение, ценностное явление [10].

Б.П. Тугаринов отмечает, что «... ответственность есть способность человека предвидеть результаты своей деятельности и определять ее исходя из того, какую пользу или 
вред она может принести обществу» [11]. В этом случае ответственность рассматривается как явление субъективного характера.

Заслуживает внимания определение ответственности, сорормулированное в фрилософрском энциклопедическом словаре: ответственность - это «философрско-социологическое понятие, отражающее объективный, исторически конкретный характер взаимоотношений между личностью, коллективом, обществом с точки зрения сознательного осуществления предъявляемых к ним требований» [12]. Общее понятие ответственности конкретизируется и детализируется в отдельных ее видах: политическая, общественная, этическая (нравственная моральная), юридическая [13] и др.

Как отмечает М.С. Строгович, «... общее определение ответственности, охватывающее все его виды и формы, вообще отсутствует», при освещении вопросов юридической ответственности значительную ценность представляет ее общее понятие, сорормулированное в «Философрском словаре», так как, во-первых, юридическая ответственность включается в это общее понятие и не противопоставляется ему, во-вторых, как общее понятие ответственности, так и юридическая ответственность определяется со стороны позитивной и негативной - как одобрение, награда за выполнение своего долга и как осуждение, взыскание, наказание за невыполнение долга, за неисполнение своих обязанностей» [14].

Таким образом, юридическая (или правовая) ответственность вытекает из понятия ответственности вообще и связана с совершением незаконных действий. Вопросы юридической ответственности разрабатывались как в научной литературе по конституционному, уголовному, административному, финансовому, трудовому праву [15], так и в работах, затрагивающих общетеоретические проблемы права.

Как отмечал О.Э. Лейст, «...обычно ответственность подразделяется на виды в зависимости от отраслей права. Но данное деление не совпадает с отраслевой структурой права уже по той причине, что видов ответственности меньше чем отраслей права, причем за нарушение нормы права различных отраслей может применяться ответственность одного и того же вида. В пределах одной отрасли права могут существовать различные виды ответственности (материальная и дисциплинарная). Кроме того, О.Э. Лейст говорит о том, что первостепенная задача - типизация видов ответственности, их укрупненная классификация [16].

К настоящему времени исследованию проблем юридической ответственности посвящено большое количество работ. Проблема понимания юридической ответственности рассматривалась в трудах С.С. Алексеева, С.Н. Братуся, О.С. Иофрое, П.Е. Недбайло, Н.И. Матузова, О.Э. Лейста, Н.С. Малеина, И.С. Самощенко, М.Д. Шаргородского, Л.С. Явича.

В теории юридической ответственности можно выделить ряд концепций относительно понимания юридической ответственности. Ряд ученых - О.С. Иофрфе, М.Д. Шарго- 
родский, Л.С. Явич и др. - связывают юридическую ответственность с противоправным поведением, которое влечет за собой государственное принуждение и наказание. Данная концепция юридической ответственности получила название - ретроспективной (негативной).

Другие ученые, например П.Е. Недбайло, Н.И. Матузов, В.С. Марков, рассматривают юридическую ответственность в более широком плане, как понятие, включающее, помимо ответственности «негативной», ответственность «позитивную» («активную», «перспективную»). Она представляется уже не только как последствие негативного явления, как реакция государства на совершенное правонарушение, а как явление позитивное, предполагающее сознательное, ответственное отношение индивида к своим поступкам, образу жизни, людям, работе, т.е. это - основа поведения субъектов, исключающая нарушение правовых предписаний.

Определенного внимания заслуживает дискуссия о теории «позитивной ответственности». В частности, Н.И. Матузов отмечает: «...речь идет не об ответственности за те или иные нарушения, сводящиеся чаще всего к наказанию, а об ответственности как определенном внутреннем состоянии индивида, его отношении к порученному делу, обществу, государству, коллективу, к своему поведению (в настоящем и будущем), чувстве самодисциплины, сознательности. Позитивная ответственность - это мера требовательности к себе и другим, глубокое понимание интересов госу- дарства, общества» [17]. В этой связи можно поддержать ученых в том, что рассмотрение негативной (ретроспективной) ответственности вне связи с активной (позитивной) ведет к умалению ее роли как инструмента регулирования и охраны общественных отношений, как средства воспитания ответственного отношения граждан к своим обязанностям [18].

Следует также согласиться, что ответственность устанавливается прежде всего для стимулирования правомерного поведения, а не для применения наказания за неисполнение правовых норм [19], т.е. главное назначение юридической ответственности в профиллактическом, превентивном применении. Юридическая ответственность в ее личностно-психологическом смысле занимает самостоятельное место в структуре правосознания, это не только факт понимания смысла предписаний правовых норм, но и выработка особого, активного отношения к ним, формирование установок правомерного поведения [20].

Д.А. Липинский, обобщив накопленный научный материал по проблеме юридической ответственности, говорит о том, что «юридическая ответственность едина и включает в себя как ответственность за будущее поведение (позитивную, добровольную, активную), так и ответственность за прошлое противоправное поведение (негативную, государственно-принудительную). Таким образом, юридическая ответственность имеет следующие формы реализации - добровольную (позитивную) и 
государственно-принудительную (негативную) [21].

К настоящему времени проделана значительная и плодотворная работа по исследованию этой важной правовой категории, но остается еще много нерешенных и дискуссионных вопросов относительно юридической ответственности в административном праве. Но перед исследованием данного вида юридической ответственности все же представляется необходимым кратко рассмотреть ряд теоретических положений, касающихся существа юридической ответственности, поскольку и относительно данной проблемы в юридической литературе имеются различные мнения, точнее сказать единого мнения по этим вопросам так и не выработано.

Как отмечает К.С. Лиховидов, «...длительная дискуссия юристов по данной проблематике оказалась весьма плодотворной. Она, вопервых, показала, каким многофакторным феноменом является ответственность, во-вторых, позволила выявить разнообразные черты содержания различных видов юридической ответственности, в-третьих, привела к выводу о необходимости дифрференцированного подхода к ответственности в зависимости от сфреры социальных отношений и социальной роли субъектов ответственности» [22].

Юридическая ответственность, являясь проявлением связи и взаимной ответственности личности и государства, - это один из существенных гарантов правопорядка, общественных и личных интересов граждан в Российской Федерации. Государство берет на себя обязанность защитить фризических и юридических лиц и само себя от противоправных виновных деяний, посягающих на защищаемые российским правом ценности. Понятие юридической ответственности - основная дефиниция всей теории ответственности, ее конструкция определяет место и роль рассматриваемого правового явления в системе права. При определении общего понятия юридической ответственности необходимо исходить, по крайней мере, из двух следующих посылок: во-первых, каково назначение института юридической ответственности в правовом регулировании, во-вторых, каковы общие для всех видов ответственности родовые свойства, не содержащие в себе несущественные случайные видовые признаки [23].

Так, О.С. Иофрфе и М.Д. Шаргородский утверждали, что юридическая ответственность есть сочетание трех элементов. Они определяют юридическую ответственность как меру государственного принуждения, основанную на юридическом общественном осуждении поведения правонарушителя и выражающуюся в установлении для него определенных отрицательных последствий в виде ограничений личного или имущественного порядка [24].

С.C. Алексеев еще в 70-х годах XX в. отмечал, что сущность юридической ответственности состоит в обязанности лица претерпевать меры государственного принудительного воздействия за совершен- 
ное правонарушение. Это мнение он отстаивал и позже [25]. И.С. Самощенко полагает, что юридическая ответственность есть особое, предусмотренное и урегулированное нормами права отношение между нарушителем требований права и государством в лице его определенных органов [26]. Отсюда «юридическая ответственность» трактуется в правовой литературе неоднозначно.

Одни авторы сводят ее только к разновидностям санкций, другие под ней подразумевают сам процесс их применения. Третьи представляют ее в виде охранительного правоотношения, возникающего между нарушителем и государственными органами. Но во всех случаях юридическая ответственность - это специфическая обязанность претерпевания лишений личного и материального характера за совершенное правонарушение в соответствии с санкцией нарушенной нормы права.

Так, В.Н. Хропанюк полагает, что юридическая ответственность означает применение санкций правовых норм, указанных мер ответственности [27]. Некоторые ученые понимают данное понятие в широком и узком смысле слова [28]. Но, несмотря на различие мнений авторов данных концепций в подходах к сущности юридической ответственности, в них выражается, по существу, два аспекта одно и того же общественного отношения: первые рассматривают юридическую ответственность с позиции совершения определенных функций государственным аппаратом [29], вторые переносят центр тя- жести на правовое положение правонарушителя [30].

В связи с этим юридическая ответственность выступает как проявление одного из способов правового регулирования - в виде наложения запретов. Запрещение, по мнению С.С. Алексеева, есть «...возложение на лиц обязанностей воздерживаться от совершения действий определенного рода» [31]. Исходя из этого, мы имеем дело с охранительным правовым институтом, который регулирует общественные отношения преимущественно посредством запретов. Как отмечает Н.С. Малеин, «...если запреты не сковывают свободу и инициативу граждан, то ответственность за нарушение запретов направлена не на подавление свободы, а служит гарантом и защитой свободы и прав личности» [32]. В.В. Курочкина говорит о том, что «юридическая ответственность выступает как проявление одного из способов правового регулирования в виде наложения запретов» [33].

Как отмечает А.П.Шергин, «...каждый вид юридической ответственности обладает только присущими ему признаками, занимает свою нишу в юрисдикционном механизме защиты общественных отношений» [34].

В отличие от уголовной ответственности административная ответственность не влечет судимости, отличается меньшей тяжестью наказания и более коротким сроком давности. Все виды юридической ответственности имеют как общие, так и частные признаки. Что касается уголовной ответственности, то наи- 
более удачное определение данному виду юридической ответственности сформулировано Н.А. Огурцовым и A.В. Наумовым. В частности, названные ученые отмечают, что уголовная ответственность представляет ту меру государственного принуждения, которая применяется в отношении лица, совершившего преступление, выступает для последнего в качестве неблагоприятного последствия за совершенное им преступление и означает отрицательную моральнополитическую оценку преступления и личности преступника со стороны государства и общества [35].

Административная ответственность за нарушения законодатель- ства о контрактной системе в сфрере закупок товаров, работ, услуг для обеспечения государственных и муниципальных нужд, что в гл. 7 КоАП РФ предусмотрена ответственность за: нарушение порядка осуществления закупок товаров, работ, услуг для обеспечения государственных и муниципальных нужд (ст. 7.30); нарушение порядка ведения реестра контрактов, заключенных заказчиками, реестра контрактов, содержащего сведения, составляющие государственную тайну, реестра недобросовестных поставщиков (подрядчиков, исполнителей) (7.31); нарушение порядка заключения, изменения контракта (7.32) и др.

\section{Библиография:}

1. Алексеев С.С. Общая теория права. Т. 1. - М., 1981. - С. 35.

2. Явич Л.С. Научно-техническая революция и юридическая наука // Правоведение. - 1973. - № $5 .-$ C. 50 .

3. Даль В.И. Толковый словарь живого великорусского языка. Т. 2. - М., 1994. - С. 1863.

4. Галаган И.А. Методологические проблемы общей теории юридической ответственности по советскому праву // Уголовная ответственность: проблемы, содержание установление, реализация. - Воронеж, 1989. - С. 11.

5. Мальцев В.В. Социальная ответственность личности, уголовное право и уголовная ответственность // Правоведение. - 2000. - № 6. - С. 154.

6. Тархов В.А. Понятие юридической ответственности // Правоведение. - 1973. - № 2. - С. 35.

7. Лейст О.Э. Санкции в советском праве. - М., 1962. - С. 94.

8. Черданцев А.Ф., Кожевников С.П. О понятии и содержании юридической ответственности // Правоведение. - 1975. - № 5. - С. 41.

9. Теория государства и права / Под ред. Н.И. Матузова, А.В. Малько. - М., 1997. - С. 540.

10. Богданова М.С. О понимании юридической ответственности в современных условиях // Юрист. - 1997. - № 7. - С. 38.

11. Тугаринов Б.П. Личность и общество. - М., 1965. - С. 52.

12. Философский энциклопедический словарь. - М., 1989. - С. 815.

13. Бельский К.С. Персональная ответственность в советском государственном управлении (понятие, формы, факторы, укрепления). - М., 1988. - С. 31

14. Строгович М.С. Сущность юридической ответственности // Сов. гос. и право. - 1979. № 5. - C. 72.

15. Якуба О.М. Административная ответственность. - М., 1972. - С. 123; Бахрах Д.Н. Административная ответственность. - М., 1999. 


\section{Полицейская деятельность 5 • 2015}

16. Лейст О.Э. Основные виды юридической ответственности за правонарушение // Правоведение. - 1977. - № 3. - С. 32.

17. Матузов Н.И. Правовая система и личность. - Саратов, 1987. - С. 196.

18. Фефелов П.А. Механизм уголовно-правовой охраны (основные методологические проблемы). - М., 1992. - С. 46-47.

19. Рыбаков В.А. Позитивная юридическая ответственность (воспитательные аспекты). - Рязань, 1988. - С. 10.

20. Юридическая психология / Под ред. Ю.В Чуфраровского. - М., 1998. - С. 244.

21. Липинский Д.А. О системе и видах юридической ответственности // Правоведение. - 2003. - № 2. - С. 28.

22. Лиховидов К.С. Материальная ответственность военнослужащих: Дис. ... канд. юрид. наук. - М., 1997. - С. 19.

23. Емельянов А.С., Черногор Н.Н. Финансово-правовая ответственность. - М., 2004. - С. 23-45.

24. Иофрфе О.С., Шаргородский М.Д. Вопросы теории права. - М., 1961. - С. 314-318.

25. Алексеев С.С. Проблемы теории права. Т. 1. - Свердловск, 1972. - С. 371.

26. Теория государства и права / Под ред. А.И. Денисова. - М., 1972. - С. 500.

27. Хропанюк В.Н. Теория государства и права. - М., 1993. - С. 242.

28. Общая теория права и государства / Под ред. В.В. Лазарева. - М., 1996. - С. 240-241.

29. Алексеев С.С. Общая теория права. Т. 1. - М., 1981. - С. 359.

30. Сыроватская Л.А. Ответственность по советскому трудовому праву. - М., 1974. - С. 183.

31. Алексеев С.С. Теория права. - М., 1997. - С. 157.

32. Малеин Н.С. Современные проблемы юридической ответственности // Государство и право. - 1994. - № 6. - С. 23.

33. Курочкина В.В. Проблемы правового регулирования материальной ответственности сотрудников органов внутренних дел Российской Федерации: Автореф. дис. ... канд. юрид. наук. - М., 2000. - С. 12.

34. Основные институты административно-деликтного права / Под ред. А.П. Шергина. - М., 1999. - С. 26.

35. Огурцов Н.А., Наумов А.В. Понятие уголовной ответственности // Труды Высшей следственной школы МВД СССР. - Волгоград, 1969. - С. 159.

36. Лапина М.А., Карпухин Д.В. Краткие выводы // Финансовое право и управление. - 2015. 2. - C. 291 - 294. DOI: 10.7256/2310-0508.2015.2.15927.

37. Куракин А.В., Калинина Н.С. Административная ответственность и ее реализация в сфрере обеспечения правопорядка при проведении собраний, митингов, демонстраций, шествий и пикетирования // Административное и муниципальное право. - 2013. - 3. - С. 270 - 279. DOI: 10.7256/1999-2807.2013.03.11.

38. Ивачев О.В., Корзун С.Ю. К вопросу о понятии налогового правонарушения в административно праве. // Административное и муниципальное право. - 2010. - 11. - С. 42 - 48.

\section{References (transliterated):}

1. Alekseev S.S. Obshchaya teoriya prava. T. 1. - M., 1981. - S. 35.

2. Yavich L.S. Nauchno-tekhnicheskaya revolyutsiya i yuridicheskaya nauka // Pravovedenie. 1973. - № 5. - S. 50.

3. Dal' V.I. Tolkovyi slovar' zhivogo velikorusskogo yazyka. T. 2. - M., 1994. - S. 1863.

4. Galagan I.A. Metodologicheskie problemy obshchei teorii yuridicheskoi otvetstvennosti po sovetskomu pravu // Ugolovnaya otvetstvennost': problemy, soderzhanie ustanovlenie, realizatsiya. - Voronezh, 1989. - S. 11. 
5. Mal'tsev V.V. Sotsial'naya otvetstvennost' lichnosti, ugolovnoe pravo i ugolovnaya otvetstvennost' // Pravovedenie. - 2000. - № 6. - S. 154.

6. Tarkhov V.A. Ponyatie yuridicheskoi otvetstvennosti // Pravovedenie. - 1973. - № 2. - S. 35.

7. Leist O.E. Sanktsii v sovetskom prave. - M., 1962. - S. 94.

8. Cherdantsev A.F., Kozhevnikov S.P. O ponyatii i soderzhanii yuridicheskoi otvetstvennosti // Pravovedenie. - 1975. - № 5. - S. 41.

9. Bogdanova M.S. O ponimanii yuridicheskoi otvetstvennosti v sovremennykh usloviyakh // Yurist. -1997 . - № 7. - S. 38.

10. Tugarinov B.P. Lichnost' i obshchestvo. - M., 1965. - S. 52.

11. Bel'skii K.S. Personal'naya otvetstvennost' v sovetskom gosudarstvennom upravlenii (ponyatie, formy, faktory, ukrepleniya). - M., 1988. - S. 31

12. Strogovich M.S. Sushchnost' yuridicheskoi otvetstvennosti // Sov. gos. i pravo. - 1979. - № 5. - S. 72.

13. Yakuba O.M. Administrativnaya otvetstvennost'. - M., 1972. - S. 123; Bakhrakh D.N. Administrativnaya otvetstvennost'. - M., 1999.

14. Leist O.E. Osnovnye vidy yuridicheskoi otvetstvennosti za pravonarushenie // Pravovedenie. 1977. - № 3. - S. 32.

15. Matuzov N.I. Pravovaya sistema i lichnost'. - Saratov, 1987. - S. 196.

16. Fefelov P.A. Mekhanizm ugolovno-pravovoi okhrany (osnovnye metodologicheskie problemy). - M., 1992. - S. 46-47.

17. Rybakov V.A. Pozitivnaya yuridicheskaya otvetstvennost' (vospitatel'nye aspekty). - Ryazan', 1988. - S. 10.

18. Lipinskii D.A. O sisteme i vidakh yuridicheskoi otvetstvennosti // Pravovedenie. - 2003. - № 2. - S. 28.

19. Likhovidov K.S. Material'naya otvetstvennost' voennosluzhashchikh: Dis. ... kand. yurid. nauk. - M., 1997. - S. 19.

20. Emel'yanov A.S., Chernogor N.N. Finansovo-pravovaya otvetstvennost'. - M., 2004. - S. 23-45.

21. loffe O.S., Shargorodskii M.D. Voprosy teorii prava. - M., 1961. - S. 314-318.

22. Alekseev S.S. Problemy teorii prava. T. 1. - Sverdlovsk, 1972. - S. 371.

23. Khropanyuk V.N. Teoriya gosudarstva i prava. - M., 1993. - S. 242.

24. Alekseev S.S. Obshchaya teoriya prava. T. 1. - M., 1981. - S. 359.

25. Syrovatskaya L.A. Otvetstvennost' po sovetskomu trudovomu pravu. - M., 1974. - S. 183.

26. Alekseev S.S. Teoriya prava. - M., 1997. - S. 157.

27. Malein N.S. Sovremennye problemy yuridicheskoi otvetstvennosti // Gosudarstvo i pravo. 1994. - № 6. - S. 23.

28. Kurochkina V.V. Problemy pravovogo regulirovaniya material'noi otvetstvennosti sotrudnikov organov vnutrennikh del Rossiiskoi Federatsii: Avtoref. dis. ... kand. yurid. nauk. - M., 2000. - S. 12.

29. Ogurtsov N.A., Naumov A.V. Ponyatie ugolovnoi otvetstvennosti // Trudy Vysshei sledstvennoi shkoly MVD SSSR. - Volgograd, 1969. - S. 159.

30. Lapina M.A., Karpukhin D.V. Kratkie vyvody // Finansovoe pravo i upravlenie. - 2015. - 2. C. 291 - 294. DOI: 10.7256/2310-0508.2015.2.15927.

31. Kurakin A.V., Kalinina N.S. Administrativnaya otvetstvennost' i ee realizatsiya v sfere obespecheniya pravoporyadka pri provedenii sobranii, mitingov, demonstratsii, shestvii i piketirovaniya // Administrativnoe i munitsipal'noe pravo. - 2013. - 3. - C. 270 - 279. DOI: 10.7256/19992807.2013.03.11.

32. Ivachev O.V., Korzun S.Yu. K voprosu o ponyatii nalogovogo pravonarusheniya v administrativno prave. // Administrativnoe i munitsipal'noe pravo. - 2010. - 11. - C. 42 - 48. 